\title{
Correction to: The Interplay Between the Microbiome and Cardiovascular Risk
}

\author{
Brè A. Minniefield ${ }^{1} \cdot$ Stella W. Aslibekyan ${ }^{1}$
}

Published online: 28 June 2018

(C) Springer Science+Business Media, LLC, part of Springer Nature 2018

\section{Correction to: Curr Genet Med Rep (2018) 6:89-97 \\ https://doi.org/10.1007/s40142-018-0142-0}

In the recently published paper, "The Interplay Between the Microbiome and Cardiovascular Risk", the last name of the lead author is listed incorrectly. The author's name is Brè A. Minniefield.

The online version of the original article can be found at https://doi.org/ 10.1007/s40142-018-0142-0

Stella W. Aslibekyan saslibek@uab.edu

1 Department of Epidemiology, School of Public Health, University of Alabama at Birmingham, 1665 University Blvd, RPHB 230J, Birmingham, AL 35294, USA 